\title{
Evaluation of five treatment regimens, using either dapsone monotherapy or several doses of rifampicin in the treatment of paucibacillary leprosy
}

\author{
S R PATTYN,* J A HUSSER $\dagger$ G BAQUILLON†, \\ M MAIGA \& P JAMET $\ddagger$ \\ *Institute for Tropical Medecine and University of Antwerp, \\ Belgium; $\dagger$ Formerly Institute Marchoux, Bamako, Mali; $\ddagger$ Departe- \\ ment de Recherche, Institute Marchoux, Bamako, Mali
}

\section{Accepted for publication 12 October 1989}

\begin{abstract}
Summary The objective of the present study was to define short-course treatment regimens for PB leprosy and to compare them with the 'classical' dapsone treatment and the WHO-PB regimen. Five treatment regimens were studied and evaluated by the histologic evolution. The regimens were: (1) dapsone $100 \mathrm{mg}$ daily, non-supervised for 3 years; (2) RMP $900 \mathrm{mg}$ supervised, once weekly, 8 doses; (3) idem 12 doses; (4) RMP $600 \mathrm{mg}$, once monthly, supervised, 6 doses and during this treatment dapsone $100 \mathrm{mg}$ daily unsupervised; (5) RMP $600 \mathrm{mg}$ together with dapsone $100 \mathrm{mg}$ daily, supervised for 6 days. For each of these regimens there were between 114 and 195 person-years of follow-up.

Results are comparable for the 5 treatment regimens, and reach $65-75 \%$ cure rates at 36 months and $80-90 \%$ at 48 months af ter the start of therapy. The relapse rate for all groups is about $0.5 \%$ per year. The difficulty for the diagnosis of relapse in PB leprosy is discussed.

It is concluded that treatment of PB leprosy can be relatively simple but that a relatively long time is needed to evaluate its effect.
\end{abstract}

\section{Introduction}

Paucibacillary (PB) leprosy patients are estimated to harbour no more than $10^{6}$ Mycobacterium leprae. ${ }^{1}$ This is 100 to 1000 times lower than the frequency of naturally appearing rifampicin resistant mutants, ${ }^{2}$ allowing treatment of PB leprosy with rifampicin (RMP) monotherapy. Furthermore, the potent and rapidly bactericidal activity of RMP allows evaluation of the efficacy of short-course antibacterial treatment regimens in PB leprosy.

In a previous study performed in Burundi and Addis Ababa ${ }^{3.4} 900$ mg RMP was administered once a week during 8 weeks to a small number of patients.

In a later study RMP was administered weekly during 10 weeks, in $900 \mathrm{mg}$ doses in 
Zaire, Rwanda and Burundi and $600 \mathrm{mg}$ doses in the Comores, with very satisfactory results. ${ }^{5}$ In the meantime there was a possibility to conduct at the Institut Marchoux in Bamako, Mali, a prospective randomized study on the efficacy, in PB leprosy, of 8 and 12 weekly doses of $900 \mathrm{mg}$ RMP compared with the 'classical' dapsone (DDS $100 \mathrm{mg}$ daily) during 3 years. In a second study in Bamako started in 1984, 2 treatment regimens were compared: the WHO-PB regimen ${ }^{6}$ and the same regimen administered during 6 days instead of 6 months.

The results of both these studies are presented in this paper.

\section{Patients and methods}

The patients presenting at the Institute Marchoux, Bamako, had a clinical, neurological and bacteriological examination, the results of which were entered, together with the disability scores on a standard form. A copy of this, together with a skin biopsy fixed in $10 \%$ formalin were sent to Antwerpen.

Patients were classified as PB when they had clinical TT or BT leprosy, a bacterial index (BI) of no more than $1+$ in none of 5-6 skin smears (2 earlobes and 3-4 other skin sites: one or two lesions, the lumbar region and front or chin), and if the skin biopsy showed a TT or BT lesion with a BI not higher than 1 .

After informed consent patients were allocated to the different groups by the use of numbered envelopes containing computor randomized treatment regimens.

The regimens were:

DDS: dapsone $100 \mathrm{mg}$ daily, unsupervised, during 3 years, the patients collecting their drugs once a month.

RMP $8 \times$ or $12 \times$ : RMP $900 \mathrm{mg}$ weekly, supervised during either 8 or 12 weeks, the patients coming to the Institute weekly. Some patients coming from far away in the country were lodged at the Institute for the duration of the treatment.

WHO-PB: RMP 600 mg once every 4 weeks, supervised, 6 doses, together with DDS 100 mg daily, unsupervised.

RMP-DDS 6d: RMP 600 mg and DDS 100 mg daily, supervised during 6 days. Patients were lodged at the Institute during treatment which started on Mondays and finished the next Saturday.

During the second study some patients ref used the WHO-PB treatment, preferring the shorter regimen RMP-DDS 6d. This explains the slightly lower number of patients in the WHO-PB regimen. Follow-up examinations were planned on a yearly frequency, but some patients showed up more frequently while many were lost for follow-up. Only those patients seen at least 12 months af ter the end of the different treatment regimens have been included in this analysis, except for those in the DDS regimen, for whom 3 years of followup were required.

During follow-up, clinical and neurological examinations were performed, and a copy of a new clinical file together with a biopsy from the lesion originally biopsied, were sent to Antwerpen. Sometimes when a lesion was entirely replaced with scars from previous biopsies, a biopsy from another lesion was taken.

The criterium for cure was the disappearance of histological lesions, the criterium for relapse was the presence of histological lesions when a previous biopsy had shown cure. 
For the analysis of the results the life table technique was applied taking into account the withdrawal of some patients.

\section{Results}

Table 1 shows for the 5 treatment regimens: the number of patients analysed, the number of patient-years of follow-up (after the start of the treatment regimens) and the cure rates observed. For the interpretation of this table, the widely differing durations of the treatment regimens should be taken into consideration: 3 years for DDS (the results after 12 and 24 months being obtained during treatment) 2 and 3 months respectively for the regimens RMP $8 \times$ and RMP $12 \times, 6$ days for RMP-DDS $6 \mathrm{~d}$ and 6 month for the WHO-PB regimen.

The histological evolution is comparable in the 5 groups, none of the differences being significant. The cure rates are $65-78 \%$ at 3 years, $78-90 \%$ at 4 years and for those who presented still later $90-100 \%$. There were no significant differences between patients with less than 3 skin lesions and those having 3 or more. The histological cures in the present studies were obtained somewhat later than in a previous study. ${ }^{2}$ There were no neurological reversal reactions leading to significant (more than 1 unit) deterioration in the disability scores.

There was a histological relapse in each treatment group and 2 in the WHO-PB group. For illustration, brief summaries of these cases are presented.

Table 1. Number of patients, patient years of follow-up and annual percentages of histological cures in PB leprosy after different treatment regimens

\begin{tabular}{|c|c|c|c|c|c|}
\hline & \multicolumn{5}{|c|}{ Treatment regimens* } \\
\hline & DDS & $\begin{array}{l}\text { RMP } \\
8 \times\end{array}$ & $\begin{array}{l}\text { RMP } \\
12 \times\end{array}$ & $\begin{array}{c}\text { OMS } \\
6 \mathrm{~d}\end{array}$ & $\begin{array}{c}\text { OMS } \\
\text { PB }\end{array}$ \\
\hline & \multicolumn{5}{|c|}{$\mathrm{n}$} \\
\hline & 33 & 46 & 40 & 73 & 60 \\
\hline & \multicolumn{5}{|c|}{ Patient years of follow-up $\dagger$} \\
\hline & 138 & 114 & 173 & 189 & 163 \\
\hline $\begin{array}{l}\text { Months after } \\
\text { start of } \\
\text { treatment }\end{array}$ & \multicolumn{5}{|c|}{$\begin{array}{c}\text { Annual percentages (after start of treatment) } \\
\text { of histopathological cures }\end{array}$} \\
\hline 12 & $18 \cdot 2$ & $21 \cdot 8$ & $22 \cdot 5$ & $38 \cdot 7$ & 34.4 \\
\hline 24 & 46.6 & $43 \cdot 5$ & 52.5 & $55 \cdot 8$ & $58 \cdot 8$ \\
\hline 36 & 68 & $65 \cdot 6$ & $67 \cdot 5$ & $77 \cdot 9$ & 71.7 \\
\hline 48 & 80 & $89 \cdot 5$ & $78 \cdot 4$ & 89 & $88 \cdot 7$ \\
\hline 60 & 92 & 100 & $89 \cdot 2$ & 100 & 100 \\
\hline 72 & 100 & & 94.6 & & \\
\hline
\end{tabular}




\section{DDS treatment (IMT 27)}

Treatment was started in 1981. Cured in 1984. In 1986, 60 months after the start of treatment, new lesions appeared which were diagnosed indeterminate (peri-neural infiltrations only).

\section{$R M P 8 \times$ treatment (IMT 54)}

Treatment started June 1981, clinical cure during 1982-7 but the last biopsies show BT granulomas in a scarred tissue.

\section{RMP $12 \times$ treatment (IMT 45)}

Treatment started in May 1981, patient seen twice a year in 1982, 1983 and 1984, clinically cured, no histologic lesions. On two occasions in 1985 a new hypochromic lesion on the elbow was seen with each time a small BT granuloma. Incubation time 48 months.

\section{$R M P-D D S 6 d$ treatment (IMT 265)}

BT leprosy in 1985. Several biopsies between 7 and 30 months after the start of therapy were negative, when biopsy was once more positive in the presence of new clinical lesions.

\section{WHO-PB treatment}

Case (IMT 142) treated in 1984 had a clinical and histological cure at 6 successive examinations. In 1987, at 37 months, in the absence of any clinical signs, 2 small granulomas were detected, no granuloma was found 5 months later.

Case (IMT 179) had a similar evolution. In October 1984 he had BT lesions over his whole body. They disinfiltrated and repigmented progressively and no lesions were found at 5 successive examinations. A biopsy in October 1988, 42 months after the end of treatment revealed a small tuberculoid granuloma.

These histologic relapses appeared after a mean and median interval of 48 months after the start of treatment.

\section{Discussion}

The regimens of 8 and 12 weekly doses of $900 \mathrm{mg}$ RMP were included in the first study reported here because at the time of its initiation, 1980, it was not clear whether 8 doses as used in the Addis Ababa-Bujumbura study conceived in 1976 and initiated in $1977^{2,3}$ would be a satisfactory treatment for PB leprosy. The $900 \mathrm{mg}$ dosage of RMP also goes back to 1976 when the optimal dosage of RMP was undecided. In 1980 it was still ethical to study dapsone monotherapy regimen as the first cases of primary dapsone resistant leprosy in Bamako were detected only in 1985, and published in 1987. ${ }^{9}$ The administration of dapsone in the RMP-DDS $6 \mathrm{~d}$ regimen is certainly without any notable antibacterial effect and could have been omitted, its presence results simply from an 
attempt to condense the WHO-PB regimen (where there is no need for the antibacterial effect of dapsone) into 1 week.

The results show that there are no differences in cure nor relapse rates between the 5 treatment regimens tested, be it the old classical DDS treatment or regimens based on RMP monotherapy.

All our studies concerning the efficacy of treatment regimens in PB leprosy are based on histopathology, because it produces objective and permanent documentation, certainly when different clinicians examine the patients.

One study ${ }^{7}$ has called attention to the discordancies that may appear between different histopathologists in the diagnosis of leprosy. However in the present and previous studies $^{4,5}$ the same person examined all the slides. Furthermore, the purpose of the study by Fine et $a l .{ }^{7}$ differs from ours. In the study by Fine et al., efforts were made to diagnose all possible cases of leprosy, whereas in our studies histopathology was applied to exclude all cases that were not histologically documented. Thus we may have excluded false negatives (patients with minimal leprosy in histopathology) but we avoided the inclusion of false positives (patients without leprosy).

It is astonishing that, as far as we know, this is the first study of the histologic evolution of PB leprosy under DDS treatment.

The slowness of the histologic cures was already noted during the first study of our laboratory ${ }^{4}$ inasmuch that in the second study ${ }^{3}$ skin biopsies at the first follow-up examination, 1 year after the start of treatment, were omitted. There is frequently a delay of the histological cure compared with the clinical one. The contrary is less frequent, although the clinical appreciation is frequently subjective, particularly when only hypochromic patches are present. The discrepancy between the clinicopathological and bacteriological evolution is particularly striking when the DDS treatment is compared with the RMP containing regimens, there being no difference in the clearing of the histopathological lesions after the administration of a very slow, or very rapid, bactericidal drug. ${ }^{8}$

Thus the slow disappearance of the granulomas from the skin points either to a longtime residence of antigens derived from the killed $M$. leprae or to a long natural life of these granulomas.

The results also show that a very small amount of bactericidal treatment is needed to cure a PB patient. This may result from two additive factors: the low number of responsible organisms in the lesions and the considerable immunologic defences of the patient. No cases of primary dapsone resistance were encountered in the DDS monotherapy group. The prevalence of primary dapsone resistance in multibacillary leprosy in Bamako between 1979 and 1983 was $42 \%{ }^{9}$ but not one case of high degree dapsone resistance, expected not to respond to the classical dosage of $100 \mathrm{mg}$ dapsone per day in man, was found.

Based on the definition of relapse as applied in this analysis, the presence of one or more epithelioid cell granulomas when a previous biopsy had shown none, there were 5 relapses. One case in the WHO-PB and RMP $8 \times$ regimens each concerned intercurrent histologic lesions without clinical symptoms. One case in the RMP $12 \times$ regimen relapsed at the sites of previous lesions; however, if the biopsies were not taken precisely at the correct sites, this case could be a treatment failure rather than a relapse (to take skin biopsies at very precise sites is not always so easy in real practice). Finally, there were two real relapses in the DDS and RMP-DDS 6d regimens at 30 and 60 months respectively, 
after the end of treatment. However, since the differential diagnosis between relapse and reversal reaction in PB leprosy is extremely difficult and mostly impossible ${ }^{10}$ some of the cases classified as relapse might well be reversal reactions.

The present study illustrates the difficulty to evaluate treatment regimens in PB leprosy within a short period of time, and how needlessly some authors have proposed to prolong the WHO-PB regimen, based on observation periods of only 6 or 12 months. ${ }^{11,12}$

The advantages of short course treatment regimens do not need further justification, and we ref er to the patients asking spontaneously for a shorter treatment regimen than the 6 months WHO-PB regimen.

We conclude that treatment of PB leprosy with 6, 8 or 12 doses of RMP administered within 6 days or 2,3 or 6 months are equivalent, but that a relatively long time is needed to evaluate their effect.

\section{References}

1 Shepard CC. Recent developments in the chemotherapy and chemoprophylaxis of leprosy. Leprologia (Argentina), 1974; 19: 230-4.

2 McDermott-Lancaster RD, Hilson GRF, Banerjee DK. 'Attempts to select rifampicin resistant Mycobacterium leprae in nude mice'. Abstr. 13th Int. Leprosy Congress, 1988. Quaderni Coop Sanit. 9.

3 Pattyn SR, Bourland J, Warndorff J, Cap A, Saerens EJ. Short course two months treatment of paucibacillary leprosy with rif ampicin. Preliminary results. Ann Soc B Méd Trop, 1979; 59: 79-85.

4 Warndorff J, Bourland J, Pattyn SR. Follow-up on short course 2 months' rifampicin treatment of paucibacillary leprosy. Lepr Rev, 1982; 53: 9-17.

5 Pattyn SR, Groenen G, Bourland J, Grillone S, Janssens L, and the collaborative Study Group for the treatment of leprosy. A controlled therapeutic trial in paucibacillary leprosy comparing a single dose of rifampicin followed by one year of daily dapsone with ten weekly doses of rifampicin. Lepr Rev, 1987; 58: $349-58$.

6 WHO Study Group. Chemotherapy of Leprosy for Control Programmes. Technical Report Series No. 657. WHO: Geneva, 1982.

7 Fine PEM, Job CK, McDougall AC, Meyers WM, Ponninghaus JM. Comparability among histopathologists in the diagnosis and classification of lesions suspected of leprosy in Malawi. Int J Lepr, 1986; 54: 614-25.

8 Shepard CC, Levy L, Fasal P. Rapid bactericidal effect of rifampicin on Mycobacterium leprae. Am J Trop Med Hyg, 1972; 21: 446-9.

9 Subcommittee on Clinical Trials of the Chemotherapy of Leprosy (Thelep) Scientific Working Group of the UNDP/World Bank/WHO Special Programme for Research and Training in Tropical Diseases. Primary dapsone resistance in Bamako and Chingleput: final report. Lepr Rev, 1987; 58: 209-18.

10 Waters MFR, Ridley DS, Ridley MJ. Clinical problems in the initiation and assessment of MDT. Lepr Rev, 1986; 57: 92-100.

11 Kar PK, Jha PK, Panayach JS, Snehi PS. A clinico-pathological study of multidrug regimen in paucibacillary leprosy. Ind J Lepr, 1988; 60: 235-41.

12 Pavithran. Relapse of paucibacillary leprosy af ter short course multidrug therapy. Ind J Le pr, 1988; 60: 2259. 